\section{The biofilm formation ability of Listeria monocytogenes isolated from meat, poultry, fish and processing plant environments is related to serotype and pathogenic profile of the strains}

\author{
Domenico Meloni, Roberta Mazza, \\ Francesca Piras, Sonia Lamon, \\ Simonetta Gianna Consolati, \\ Anna Mureddu, Rina Mazzette \\ Department of Veterinary Medicine, \\ University of Sassari, Italy
}

\begin{abstract}
In the present study, the relationships between serotype, pathogenic profile and in vitro biofilm formation of 106 Listeria monocytogenes strains, having no epidemiological correlation and isolated from different environmental and food sources, were analyzed. The quantitative assessment of the in vitro biofilm formation was carried out by using a microtiter plate assay with spectrophotometric reading (OD620). The isolates were also submitted to serogrouping using the target genes $1 \mathrm{mo} 0737$, Imo1118, ORF2819, ORF2110, prs, and to the evaluation of the presence of the following virulence genes: prfA, $h l y A, r r n$, inlA, inlB, iap, $p l c A, p l c B, a c t A$ and $m p l$, by multiplex PCRs. The $62 \%$ of the strains showed weak or moderate in vitro ability in biofilm formation, in particular serotypes $1 / 2 \mathrm{~b}$ and $4 \mathrm{~b}$, frequently associated with sporadic or epidemic listeriosis cases. The $25 \%$ of these isolates showed polymorphism for the actA gene, producing a fragment of 268-bp instead of the expected 385-bp. The deletion of nucleotides in this gene seems to be related to enhanced virulence properties among these strains. Strains belonging to serotypes associated with human infections and characterized by pathogenic potential are capable to persist within the processing plants forming biofilm.
\end{abstract}

\section{Introduction}

Listeria monocytogenes is widespread in the environment including soil, water, sewage, vegetation, wild animal faeces, as well as on the farm and in food processing facilities. ${ }^{1,2} L$. monocytogenes has been isolated from several processing environments (fish, meat, dairy products) and is responsible for numerous outbreaks associated with the consumption of ready to eat products. ${ }^{3}$ The pathogen is able to survive at a broad range of temperature (from 0 to $45^{\circ} \mathrm{C}$ ) and $\mathrm{pH}$ (from 4.5 to 9.0 ), high salt concentrations (10\%) and low aw values (0.92). ${ }^{4}$ L. monocytogenes, once introduced in the processing plants, is able to survive for long times under adverse environmental conditions and persists over time in niches as drains, walls, ceilings, storage tanks, hand trucks and conveyor belts, where food residues are accumulated.2,5-7

This can be explained with the ability of $L$. monocytogenes to form assemblages of surface-associated microbial cells, enclosed in hydrated extracellular polymeric substances and grow in biofilms on surfaces in contact or not with the food. 5 The biofilm structure protects the microorganism from physical (scrubbing) and chemical (sanitizers and detergents) factors. ${ }^{8}$ It has been shown that different strains of $L$. monocytogenes can differ in their abilities to form biofilms. ${ }^{9}$ In the literature conflicting opinions can be found: several authors found a correlation between serotype, pathogenic profile and ability to form biofilm;10,11 on the contrary, other authors reported not such correlation. ${ }^{12,13}$ The presence of the pathogen on surfaces in contact and without any contact with food increases the food safety risk. ${ }^{14,15}$ Thus, $L$. monocytogenes may become an important source of secondary contamination of food products and the effective control of its presence in the processing environments is a challenge for food processors. ${ }^{16}$ It is essential to characterize $L$. monocytogenes strains in order to carry out epidemiological studies and to trace the sources of contamination in the food chain. ${ }^{17}$ Serotyping has been widely used and although its discrimination power is poor, it still remains the traditional and routinely used typing method in case of outbreaks. ${ }^{18}$ Among the $13 L$. monocytogenes serotypes, only $1 / 2 \mathrm{a}, 1 / 2 \mathrm{~b}$, $1 / 2 \mathrm{c}$ and $4 \mathrm{~b}$ have been associated with epidemic and sporadic cases of listeriosis in humans. ${ }^{19}$ In particular, serotypes 1/2a, 1/2b and $4 \mathrm{~b}$ are responsible for $95 \%$ of human infections from which the majority of outbreaks are caused by strains of serotype $4 \mathrm{~b} .{ }^{20}$ In recent years, the proportion of human cases associated with strains of serotype $1 / 2 \mathrm{a}$ has increased.21,22 The molecular pathogenesis of L. monocytogenes is determined by multiple key virulence factors, such as internalins, haemolysin, phospholipases, actin polymerization protein and other minor virulence factors such as extracellular proteins (iap), antioxidant factors, metal ion uptake systems and stress response mediators. The expression of these virulence factors is directly modulated by the regulator gene $p r f A .{ }^{23}$ Recent studies have shown that the prfa gene has a significant positive impact on extracellular biofilm formation. ${ }^{24}$ Mutants lacking $p r f A$ were defective in
Correspondence: Domenico Meloni, Department of Veterinary Medicine, University of Sassari, Via Vienna 2, 07100, Sassari, Italy.

Tel. +39.079 .229570 - Fax: +39.079 .229458$

E-mail: dmeloni@uniss.it

Key words: Listeria monocytogenes, serotype, pathogenic profile, biofilm.

Acknowledgements: we wish to thank Prof. Adriana Ianieri and her collegue Dr. Mauro Conter, from the Department of Animal Production, Veterinary Biotechnologies, Food Quality and Safety, University of Parma, who have sent strains of Listeria monocytogenes to the Department of Animal Biology in Sassari

Contributions: RoM, SL, SGC, acquisition, analysis and interpretation of data; FP, AM, conception and design, acquisition, analysis and interpretation of data, drafting and revising the manus; RiM, conception and design, drafting and revising the paper.

Conflict of interests: the authors report no conflict of interests.

Received for publication: 2 December 2011. Revision received: 17 January 2012.

Accepted for publication: 17 January 2012.

This work is licensed under a Creative Commons Attribution NonCommercial 3.0 License (CC BYNC 3.0).

(C) Copyright D. Meloni et al., 2012

Licensee PAGEPress srl, Italy

Veterinary Science Development 2012; 2:e12

doi:10.4081/vsd.2012.e12

surface-adherent biofilm formation. The objective of the present study was to evaluate the relationships between serotype, pathogenic profile and in vitro biofilm formation capacity of $L$. monocytogenes strains isolated from meat, poultry, fish and the environments of the respective processing plants.

\section{Materials and Methods}

\section{Selection of the bacterial strains}

In this study, 106 L. monocytogenes strains recovered from meat, poultry, fish samples and the respective processing plants with no apparent epidemiological relations were examined. The strains were collected in a period from 2005 to $2010.40 \%$ of the isolates were collected from swine (n.14) and poultry (n.13) carcasses, pork ground meat (n.7) and raw salmon (n.6). These isolates were grouped as raw material (RM). 3\% of the strains (n.3) was isolated from semi-finished salmon (SFP), 15\% from fermented sausages (n.11) and smoked salmon (n.4), 
grouped as final products (FP). The remaining $42 \%$ came from the environments of swine slaughterhouse (n.4), fermented sausage (n.25) and smoked salmon (n.17) processing plants. In order to standardize the elaboration of these data, the environmental strains were grouped in two categories, according to the possibility to come in contact with food: surfaces without contact with food (SWCF) and surfaces with contact with food (SCF).

\section{Characterization of the strains}

Multiplex polymerase chain reaction-based serotyping

The isolates were submitted to a multiplex polymerase chain reaction (PCR) method to identify $L$. monocytogenes serotypes. ${ }^{25}$ The target genes and the sequence of each primer (Roche diagnostics, Milan, Italy) are described in Supplementary Table 1. All amplification reactions were performed in a final volume of $100 \mu \mathrm{L}$, containing $2 \mathrm{U}$ of $\mathrm{Taq}$ polymerase (Roche diagnostics), $0.2 \mathrm{~mm}$ of deoxynucleoside triphosphate (dNTP), and $50 \mathrm{~mm}$ Tris$\mathrm{HCl}-10 \mathrm{~mm} \mathrm{KCl}-50 \mathrm{~mm}\left(\mathrm{NH}_{4}\right) 2 \mathrm{SO}_{4}-2 \mathrm{mM}$ $\mathrm{MgCl}_{2}, \mathrm{pH}$ 8.3. All amplification reactions were performed in a Gene Amp 2700 Thermal Cycler (Applied Biosystems, Foster City, CA, USA) programmed as follows: initial denaturation at $94^{\circ} \mathrm{C}$ for $3 \mathrm{~min}, 35$ cycles at $94^{\circ} \mathrm{C}$ for $0.40 \mathrm{~min}$, $53^{\circ} \mathrm{C}$ for $1.15 \mathrm{~min}$ and extension at $72^{\circ} \mathrm{C}$ for $1.15 \mathrm{~min}$, followed by a final extension period at $72^{\circ} \mathrm{C}$ for $7 \mathrm{~min}$. The multiplex PCR products were resolved by electrophoresis on $1.5 \%$ agarose gel in 1X TAE and stained with ethidium bromide $(0.1 \mathrm{mg} / \mathrm{mL})$ for $20 \mathrm{~min}$. The gel images were visualized and captured using the Gel-Doc UV trans-illuminator (Bio-Rad, Hercules, CA, USA).

Multiplex polymerase chain reaction analysis of virulence factors

Three multiplex PCRs were standardized in order to detect the following 10 virulence associated genes: multiplex PCR 1): $r r n, h l y A$, actA and prfA; multiplex PCR 2): inlA, inlB and iap; multiplex PCR 3): plcA, plcB and $m p l$ by modifying the protocols of Border et al. ${ }^{26}$ and Jaradat et al. ${ }^{27}$ All amplification reactions were performed in a final volume of $50 \mu \mathrm{L}$, containing $2 \mu \mathrm{L}$ of DNA, $5 \mathrm{U}$ of Taq polymerase (Roche diagnostics), $0.2 \mathrm{mmL}-1$ of each deoxynucleoside triphosphate (dNTP), 1X PCR buffer (1.5 mmL-1 MgCl $2,50 \mathrm{mmL}-1 \mathrm{KCl}$, 10 mmL-1 Tris-HCl, pH 8.3). Supplementary Table 2 lists the concentration of each primer (Roche diagnostics) used in the three multiplex PCRs. All amplification reactions were performed in a Gene Amp 2700 Thermal Cycler (Applied Biosystems) programmed as follows: for multiplex PCR 1, denaturation at $94^{\circ} \mathrm{C}$ for $1.20 \mathrm{~min}$, annealing at $55^{\circ} \mathrm{C}$ for 1.30 min and extension at $72^{\circ} \mathrm{C}$ for $2 \mathrm{~min}$, followed by a final extension period at $72^{\circ} \mathrm{C}$ for $10 \mathrm{~min}$. For multiplex PCR 2 and 3, cycles were as follows: initial denaturation at $94^{\circ} \mathrm{C}$ for $3 \mathrm{~min}$, 35 cycles of denaturation at $94^{\circ} \mathrm{C}$ for $1 \mathrm{~min}$, annealing at $60^{\circ} \mathrm{C}$ for $2 \mathrm{~min}$, and extension at $72^{\circ} \mathrm{C}$ for $1 \mathrm{~min}$, followed by a final extension at $72^{\circ} \mathrm{C}$ for $5 \mathrm{~m}$. The amplified fragments were separated by $1.3 \%$ agarose gel electrophoresis (Roche diagnostics) in 1X.

TAE buffer and stained with ethidium bromide $(10 \mathrm{mg} / \mathrm{mL})$. The gels were observed and digitalized by the Gel-Doc UV trans-illuminator (Bio-Rad).

\section{In vitro biofilm formation}

The quantitative assessment of the in vitro biofilm formation was carried out on 96 - well polystyrene microtiter plates using the method described by Stepanovic et al.28 with some modifications. Isolates were grown for $24 \mathrm{~h}$ in $2 \mathrm{~mL}$ of BHI broth. All the wells of a microtiter plate were filled up with $230 \mu \mathrm{L}$ of BHI broth. Afterwards, 21 wells per strain were filled up with $20 \mu \mathrm{L}$ of culture. Each plate included 12 wells of BHI broth without inoculum, as negative control. Microtiter plates were incubated at $37^{\circ} \mathrm{C}$ for 20 and $40 \mathrm{~h}$. At the end of the incubation the content of the wells was removed and the plates washed three times with $300 \mathrm{~mL}$ of sterile distilled water in order to remove loosely attached bacteria. The remaining attached bacteria were fixed with $250 \mu \mathrm{L}$ of methanol per well, and after 15 min the wells were emptied and air dried. Each well was stained with $250 \mu \mathrm{L}$ of Crystal violet for $5 \mathrm{~min}$. After staining, the plates were washed under running tap water, then air dried and the dye bound to the adherent cells was resolubilized with $250 \mu \mathrm{L}$ of $33 \%$ (v/v) glacial acetic acid per well. The plates were read spectrophotometrically (OD620) using a Sunrise RC absorbance reader (Tecan, Maennedorf, Switzerland). The strains were divided up into four categories: no biofilm producers ( $\mathrm{NP}=0 . \mathrm{D} .<0.5)$, weak producers (WP $=0 . \mathrm{D} . \geq 0.5<1.0$ ), moderate producers $(\mathrm{MP}=0 . \mathrm{D} . \geq 1.0<1.5)$ and strong producers ( $\mathrm{SP}=0 . \mathrm{D} . \geq 1.5)$.

\section{Statistical analysis}

The relationships between biofilm formation, serotype and pathogenic profile were evaluated by one-way analysis of variance (ANOVA) using the GLM procedures. The mean differences between serotypes and pathogenic profiles of the $L$. monocytogenes strains in the in vitro biofilm formation ability after incubation at $37^{\circ} \mathrm{C}$ for 20 and $40 \mathrm{~h}$ were evaluated using the LSD test. Significance was defined as $\mathrm{P}<0.05$. Statistical analysis was conducted using Statgraphics Plus 5.1, software (StatPoint, Warrenton, USA).

\section{Results}

\section{Multiplex polymerase chain reaction-based Serotyping}

All the strains included in the study belonged to the $L$. monocytogenes serotypes associated with epidemic and sporadic cases of listeriosis in humans (1/2a, 1/2b, 1/2c and $4 b)$. Using multiplex PCR primers developed by Doumith et al.25 $34 \%$ of the $L$. monocytogenes isolates were recognized as $1 / 2 \mathrm{a}, 33 \%$ as $1 / 2 \mathrm{~b}$, $24 \%$ as $1 / 2$ c, $9 \%$ as 4 b (Table 1 ).

\section{Multiplex polymerase chain reaction analysis of virulence factors}

Multiplex-PCR products of the 10 virulenceassociated genes were obtained from all $106 \mathrm{~L}$. monocytogenes strains included in this study. Genotyping yielded 10 different pathogenic profiles (Table 2): the prevalent was n.3 (49\%, 9 virulence associated genes, lack of inlB) followed by n.1 (24\%, 10 virulence associated genes, complete pathogenic profile) and n.2 (16\%, 9 virulence associated genes, lack of $\mathrm{mpl}$ ). In general, PCR products of the virulence associated genes did not show polymorphism except for the actA gene. ${ }^{27}$ Eighty-one strains (76\%) showed the expected 385-bp amplicon, whereas twenty-five strains (24\%) showed the 268-bp amplicon.

Table 1. Prevalence of serotypes in the $106 \mathrm{~L}$. monocytogenes strains in relation to the source of isolation.

\begin{tabular}{lccccc} 
Source of isolation & $N^{\circ}$ of strains & \multicolumn{5}{c}{ Serotypes (\%) } \\
SWCF & \multicolumn{1}{c}{$\mathbf{1 / 2 \mathrm { a }}$} & $\mathbf{1 / 2 b}$ & $\mathbf{1 / 2 c}$ & $\mathbf{4 b}$ \\
SCF & 16 & 12.6 & 75 & 6.2 & 6.2 \\
\hline RM & 29 & 31 & 38 & 17.2 & 13.8 \\
SFP & 37 & 43.3 & 8,1 & 40.5 & 8.1 \\
FP & 9 & 33.3 & 44.4 & - & 22.3 \\
Total & 15 & 40 & 33.3 & 26.7 & - \\
\hline
\end{tabular}

SWCF, surfaces without contact with food; SCF, surfaces with contact with food; RM, raw materials; SFP, semifinished products; FP, finished products. 


\section{Quantitative assessment of in vitro biofilm formation}

Sixty-two percent (62\%) of the strains showed weak or moderate in vitro ability to form biofilm (Table 3). After $20 \mathrm{~h}$ of incubation (Figure 1), 75\% of the strains was NP, 24\%WP and 1\%MP. At the end of $40 \mathrm{~h}$ of incubation (Figure 2), $49 \%$ of the strains were NP, while the prevalence of WP and MP increased up to 49 and $2 \%$ respectively. In agreement with Djordevic et al., 10 ANOVA showed a statistically significant relationship between serotypes $1 / 2 \mathrm{~b}-4 \mathrm{~b}$ and in vitro biofilm production after 40 $\mathrm{h}(\mathrm{P}<0.05)$, also confirmed by the LSD test (Figure 3). Moreover, a statistically significant relationship was also found between pathogenic profile n.4 (9 virulence associated genes, lack of $h l y A)$ and in vitro biofilm production after 20 and $40 \mathrm{~h}$ of incubation $(\mathrm{P}<0.01)$. 0 n the whole, the LSD test showed statistically significant differences $(\mathrm{P}<0.05)$ between the mean values of the pathogenic profile n.4 associated with $1 / 2 \mathrm{~b}$ and $4 \mathrm{~b}$ serotypes and the other pathogenic profiles (Figure 4). The microtiter plate assay confirmed its utility as an indirect method of assessing the ability of $L$. monocytogenes strains to attach to abiotic surfaces, enabling researchers to rapidly analyze the adhesion of multiple bacterial strains within each experiment. ${ }^{28}$

\section{Discussion and Conclusions}

As listeriosis is essentially caused by a food source contaminated along the food chain, ${ }^{29}$ it is important to investigate the molecular characteristics and persistence ability of L.monocytogenes strains recovered from different food sources or environments in order to design and implement more effective prevention strategies. In this study, we have characterized $L$. monocytogenes strains isolated from raw materials, finished products and environmental samples by serotyping and definition of the pathogenic profile (10 different virulence-associated genes). It is notable that $67 \%$ of the $L$. monocytogenes food and environmental isolates from Italy belonged to serotypes $1 / 2 \mathrm{a}(34 \%)$ and $1 / 2 \mathrm{~b}$ (33\%). A similar prevalence was reported by other studies carried out in France, ${ }^{30}$ China, ${ }^{31}$ Italy and Switzerland. ${ }^{32,33}$ Genotyping yielded 10 different pathogenic profiles, and surprisingly only $24 \%$ of the strains tested in this study were positive for all the considered virulence genes.

Table 2. Correlations between source of isolation, pathogenic profile and serotype.

\begin{tabular}{|c|c|c|c|c|}
\hline Source of isolation & $\mathrm{N}^{\circ}$ of strains & $\begin{array}{l}\text { Pathogenic } \\
\text { profile }\end{array}$ & $\begin{array}{l}\mathrm{N}^{\circ} \text { of strains } \\
\text { and serotypes }\end{array}$ & Virulence associated genes \\
\hline SWCF & 16 & $\begin{array}{c}1 \\
2 \\
5 \\
9 \\
10\end{array}$ & $\begin{array}{c}5(4,1 / 2 \mathrm{~b} ; 1,1 / 2 \mathrm{c}) \\
8(1 / 2 \mathrm{~b}) \\
1(4 \mathrm{~b}) \\
1(1 / 2 \mathrm{a}) \\
1(1 / 2 \mathrm{a})\end{array}$ & $\begin{array}{l}\text { prfA, hlyA, rrn, inlA, inlB, iap, plcA, plcB, actA, mpl } \\
\text { prfA, hlyA, rrn, inlA, inlB, iap, plcA, plcB, actA } \\
\text { prfA, hlyA, rrn inlB, iap, plcA, plcB, actA } \\
\text { prfA, iap, plcA, plcB, actA, mpl } \\
\text { prfA, iap, plcA, plcB, actA }\end{array}$ \\
\hline SCF & 29 & $\begin{array}{l}1 \\
2 \\
3 \\
5 \\
9\end{array}$ & $\begin{array}{c}4(2,1 / 2 \mathrm{~b} ; 2,1 / 2 \mathrm{c}) \\
5(2,1 / 2 \mathrm{~b} ; 3,4 \mathrm{~b}) \\
18(8,1 / 2 \mathrm{a} ; 7,1 / 2 \mathrm{~b} ; 3,1 / 2 \mathrm{c} \\
1(4 \mathrm{~b}) \\
1(1 / 2 \mathrm{a})\end{array}$ & $\begin{array}{l}\text { prfA, hlyA, rrn, inlA, inlB, iap, plcA, plcB, actA, mpl } \\
\text { prfA, hlyA, rrn, inlA, inlB, iap, plcA, plcB, actA } \\
\text { prfA, hlyA, rrn, inlA, iap, plcA, plcB, actA, mpl } \\
\text { prfA, hlyA, rrn inlB, iap, plcA, plcB, actA } \\
\text { prfA, iap, plcA, plcB, actA, mpl }\end{array}$ \\
\hline RM & 37 & $\begin{array}{l}1 \\
2 \\
3 \\
7\end{array}$ & $\begin{array}{c}14(6,1 / 2 \mathrm{a} ; 1,1 / 2 \mathrm{~b} ; 7,1 / 2 \mathrm{c}) \\
3(4 \mathrm{~b}) \\
19(101 / 2 \mathrm{a} ; 1,1 / 2 \mathrm{~b} ; 8,1 / 2 \mathrm{c}) \\
1(1 / 2 \mathrm{~b})\end{array}$ & $\begin{array}{l}\text { prfA, hlyA, rrn, inlA, inlB, iap, plcA, plcB, actA, mpl } \\
\text { prfA, hlyA, rrn, inlA, inlB, iap, plcA, plcB, actA } \\
\text { prfA, hlyA, rrn, inlA, iap, plcA, plcB, actA, mpl } \\
\text { prfA, inlA, iap, plcA, plcB, actA, mpl }\end{array}$ \\
\hline SFP & 9 & $\begin{array}{l}1 \\
3 \\
4 \\
6\end{array}$ & $\begin{array}{c}2(4 \mathrm{~b}) \\
4(3,1 / 2 \mathrm{a} ; 1,1 / 2 \mathrm{~b}) \\
2(4 \mathrm{~b}) \\
1(1 / 2 \mathrm{~b})\end{array}$ & $\begin{array}{l}\text { prfA, hlyA, rrn, inlA, inlB, iap, plcA, plcB, actA, mpl } \\
\text { prfA, hlyA, rrn, inlA, iap, plcA, plcB, actA, mpl } \\
\text { prfA, rrn, inlA, inlB, iap, plcA, plcB, actA, mpl } \\
\text { prfA, inlA, inlB, iap, plcA, plcB, actA, mpl }\end{array}$ \\
\hline FP & 15 & $\begin{array}{l}1 \\
2 \\
3 \\
7 \\
8\end{array}$ & $\begin{array}{c}1(1 / 2 \mathrm{~b}) \\
1(1 / 2 \mathrm{a}) \\
11(4,1 / 2 \mathrm{a} ; 3,1 / 2 \mathrm{~b} ; 4,1 / 2 \mathrm{c}) \\
1(1 / 2 \mathrm{a}) \\
1(1 / 2 \mathrm{~b})\end{array}$ & $\begin{array}{l}\text { prfA, hlyA, rrn, inlA, inlB, iap, plcA, plcB, actA, mpl } \\
\text { prfA, hlyA, rrn, inlA, inlB, iap, plcA, plcB, actA } \\
\text { prfA, hlyA, rrn, inlA, iap, plcA, plcB, actA, mpl } \\
\text { prfA, inlA, iap, plcA, plcB, actA, mpl } \\
\text { prfA, rrn, plcA, plcB, actA, mpl }\end{array}$ \\
\hline
\end{tabular}

SWCF, surfaces without contact with food; SCF, surfaces with contact with food; RM, raw materials; SFP, semifinished products; FP, finished products.

Table 3. Formation of biofilm in the $106 \mathrm{~L}$. monocytogenes strains in relation to the source of isolation.

\begin{tabular}{|c|c|c|c|c|c|c|c|c|c|}
\hline \multirow[t]{3}{*}{ Source of isolation } & \multirow[t]{3}{*}{$\mathrm{N}^{\circ}$ of strains } & & \multicolumn{7}{|c|}{ Biofilm formation (\%) } \\
\hline & & \multicolumn{4}{|c|}{$20 \mathrm{~h}$} & \multicolumn{4}{|c|}{$40 \mathrm{~h}$} \\
\hline & & NP & WP & MP & SP & NP & WP & MP & SP \\
\hline SWCF & 16 & 68.8 & 25 & 6.2 & - & 50 & 37.5 & 12.5 & - \\
\hline SCF & 29 & 82.8 & 17.2 & - & - & 34.4 & 65.6 & - & - \\
\hline RM & 37 & 78.4 & 21.6 & - & - & 62.2 & 37.8 & - & - \\
\hline SFP & 9 & 66.7 & 33.3 & - & - & 22.3 & 77.7 & - & - \\
\hline $\mathrm{FP}$ & 15 & 66.7 & 33.3 & - & - & 60 & 40 & - & - \\
\hline Total & 106 & 75 & 24 & 1 & - & 49 & 49 & 2 & - \\
\hline
\end{tabular}

SWCF, surfaces without contact with food; SCF, surfaces with contact with food; RM, raw materials; SFP, semifinished products; FP, finished products; NP, no biofilm producers; WP, weak producers; MP, moderate producers; SP, strong producers. 

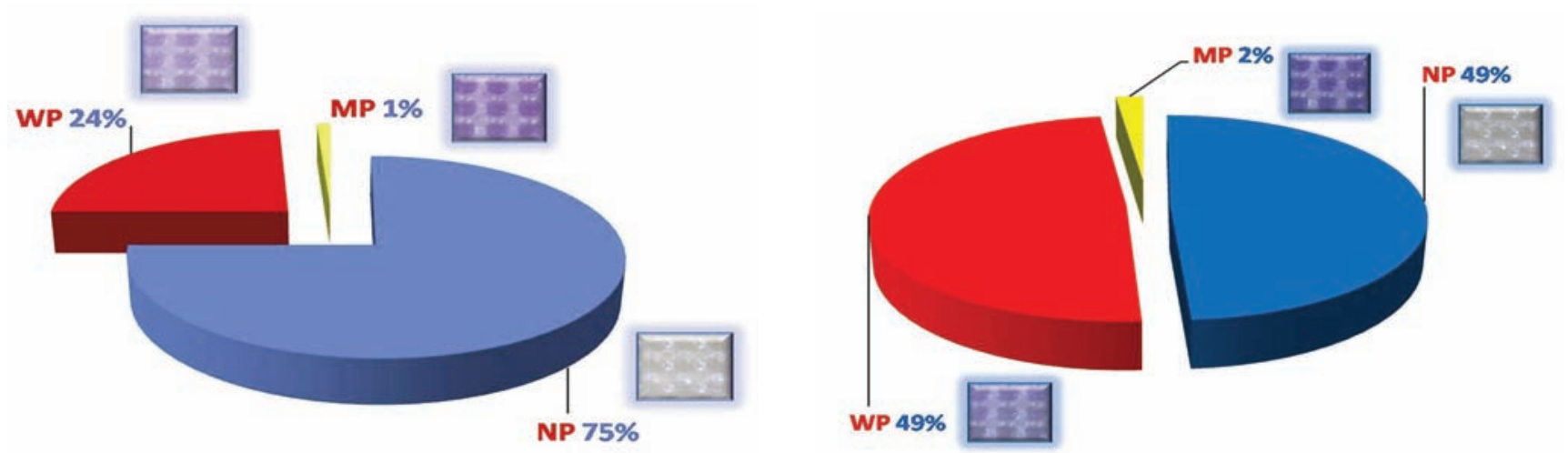

Figure 1. Formation of biofilm after 20 hours of incubation.

Means and 95,0 Percent LSD Intervals

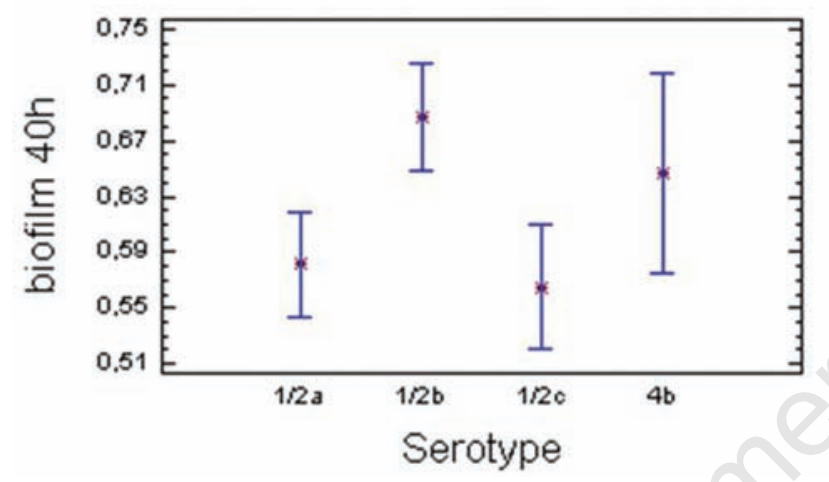

Figure 3. Relationships between serotype and formation of biofilm after $\mathbf{4 0}$ hours of incubation by means of one-way analysis of variance.

\section{Means and 95,0 Percent LSD Intervals}

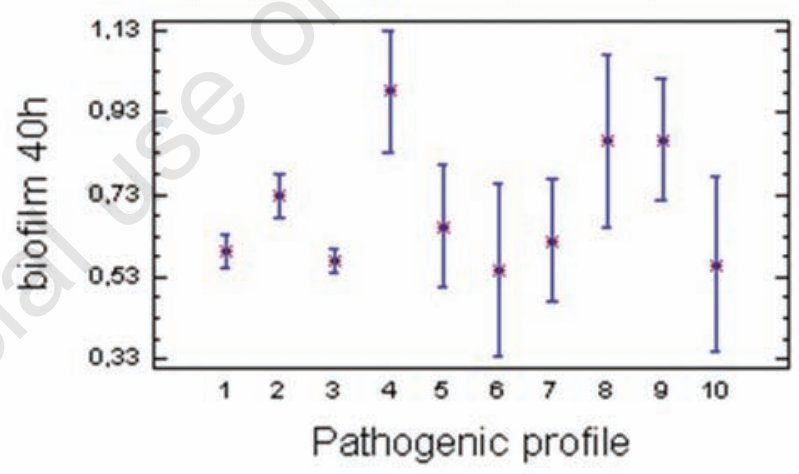

Figure 4. Relationships between pathogenic profile and formation of biofilm after 40 hours of incubation by means of one-way analysis of variance.
In general, PCR products of the virulence-associated genes did not show polymorphism except for the actA gene. ${ }^{27}$ The actA gene has been found to be important for the spread of $L$. monocytogenes to neighboring cells and maintenance of infection.23 Twenty-five strains (25\%) showed polymorphism producing a fragment of 268-bp instead of the expected 385-bp. The deletion of nucleotides in this gene seems to be related to enhanced virulence properties among these strains. ${ }^{34}$ On the contrary, other authors did not observed statistical correlations between the ownership of the 268-bp actA and the ability to invade HeLa cells in vitro. ${ }^{32}$ Several authors reported polymorphism for other virulence-associated genes, such as hlyA, iap and inlA, inlB. ${ }^{35,36}$ However, in this study, we did not identify any polymorphism in the PCR products of the other virulence associated genes. As reported by Franciosa et al.,37 the low actA PCR product was related to the serotype of the strains (1/2b). On the whole, $62 \%$ of the isolates showed weak or moderate in vitro ability to form biofilm, in particular strains isolated from SWCF as floor drains. Floor drains can be a critical site to the control of contamination of the processing plant environment: decontamination is especially challenging because, when entrapped in a biofilm, $L$. monocytogenes is afforded unusual protection against available disinfectants and treatments.5,38,39 By means of statistical analysis, the relationships between biofilm formation, serotype and pathogenic profile were evaluated. ANOVA showed statistically significant differences in terms of in vitro biofilm formation (Figures 3 and 4): strains belonging to the evolutionary lineage I (serotypes $1 / 2 b$ and $4 b$ ) were characterized by a nearly complete pathogenic profile ( 9 virulence associated genes, lack of $h l y A$ ) and by an $a c t A$ product of 268-bp. These strains showed better ability to form biofilm in vitro. From a risk analysis perspective it is important to investigate the molecular characteristics and the ability of $L$. monocytogenes to persist in the food processing environments. ${ }^{32}$ In this study, $L$. monocytogenes strains isolated from critical sites in terms of control of processing environment contamination (floor drains) and belonging to serotypes associated with human infections, were characterized by pathogenic potential and were capable to form biofilms on abiotic surfaces. The polystyrene surfaces used for this in vitro experiment approximately mimics some of the plastic materials used in the processing plants. Further testing with other plastic and steel specimens are needed in order to 
better understand the mechanism of in vivo biofilm formation and persistence within the processing plants These findings should help the Food Business Operators when designing and implementing more effective strategies to manage and control the presence of the pathogen in the food processing environments.

\section{References}

1. Sauders BD, Wiedmann M. 2007. Ecology of Listeria species and $L$. monocytogenes in the natural environment. In: Ryser ET, Marth EH. Listeria, listeriosis, and food safety. New York: Marcel Dekker; pp. 21-53.

2. Todd ECD, Notermans S. Surveillance of listeriosis and its causative pathogen, Listeria monocytogenes. Food Cont 2011;22:1484-90.

3. U.S. FDA/USDA/CDC, 2003. Quantitative assessment of the relative risk to public health from foodborne Listeria monocytogenes among selected categories of ready toeat foods. Available from: http//www.foodsafety.gov/ dms//mr2-toc.html.

4. Ryser ET, Marth EH. Listeria, listeriosis and food safety, 3rd ed. Boca Raton, FL: CRC Press; 2007.

5. Gandhi M, Chikindas ML. Listeria: a foodborne pathogen that knows how to survive. Int J Food Microbiol 2007;1:1-15.

6. López V, Villatoro D, Ortiz S, et al. Molecular tracking of Listeria monocytogenes in an Iberian pig abattoir and processing plant. Meat Sci 2008;78:130-4.

7. Poimenidou S, Belessi CA, Giaouris ED, et al. Listeria monocytogenes attachment to and detachment from stainless steel surfaces in a simulated dairy processing environment. Appl Environ Microbiol 2009;75: 7182-8.

8. Cruz CD, Fletcher GC. Prevalence and biofilm-forming ability of Listeria monocytogenes in New Zealand mussel (Perna canaliculus) processing plants. Food Microbiol 2011;28:1387-93.

9. Lunden JM, Miettinen MK, Autio TJ, Korkeala HJ. Persistent Listeria monocytogenes strains show enhanced adherence to food contact surface after short contact times. J Food Prot 2000;63:1204-7.

10. Djordjevic D, Wiedmann M, McLand sborough LA. Microtiter plate assay for assessment of Listeria monocytogenes biofilm formation. Appl Environ Microbiol 2002;68:2950-8.

11. Takahashi $\mathrm{H}$, Miya $\mathrm{S}$, Igarashi $\mathrm{K}$, et al. Biofilm formation ability of Listeria monocytogenes isolates from raw ready-to-eat seafood. J Food Prot 2009;72:1476-80.

12. Borucki MK, Peppin JD, White D, et al. Variation in biofilm formation among strains of Listeria monocytogenes. Appl Environ Microbiol 2003;69:7336-42.

13. Folsom JP, Siragusa GR, Frank JF. Formation of biofilm at different nutrient levels by various genotypes of Listeria monocytogenes. $\mathrm{J}$ Food Prot 2006;69:826-34.

14. Kim KY, Frank JF. Effect of nutrients on biofilm formation by Listeria monocytogenes on stainless steel. J Food Prot 1995;24-8.

15. Rieu A, Lemaître J-P, Guzzo J, Piveteau P. Interactions in dual species biofilms between Listeria monocytogenes EGD-e and several strains of Staphylococcus aureus. Int. J. FoodMicrobiol. 2008;126:76-82.

16. Samelis J, Metaxopoulos J. Incidence and principal sources of Listeria spp. and Listeria monocytogenes contamination in processed meats and a meat processing plant. Food Microbiol 1999;465-77.

17. Vitas AI, Aguado V, Garcia-Jalon I. Occurrence of Listeria monocytogenes in fresh and processed foods in Navarra (Spain). Int J Food Microbiol 2004;90:34956.

18. Aarnisalo K, Lunden J, Korkeala H, Wirtanen G. Susceptibility of Listeria monocytogenes strains to disinfectants and chlorinated alkaline cleaners at cold temperatures. LWT Food Sci Technol 2007;40:1041-8.

19. Nakamura H, Hatanaka M, Ochi K, et al. Listeria monocytogenes isolated from coldsmoked fish products in Osaka City, Japan. Int J Food Microbiol 2004;94:323-8.

20. Dussurget 0. New insight into determinants of Listeria monocytogenes virulence. Int Rev Cell Mol Biol 2008;270:1-38.

21. Gianfranceschi MV, D'Ottavio MC, Gattuso A, et al. Distribution of serotypes and pulsotypes of Listeria monocytogenes from human, food and environmental isolates (Italy 2002-2005). Food Microbiol 2009; 26:520-6.

22. Allerberger F, Wagner M. Listeriosis: a resurgent foodborne infection. Clin Microbiol Infect 2010;16:16-23.

23. Vazquez-Boland JA, Kuhn M, Berche P, et al. Listeria pathogenesis and molecular virulence determinants. Clin Microbiol Rev 2001;14:560-84.

24. Lemon KP, Freitag NE, Kolter R. The virulence regulator PrfA promotes biofilmformation by Listeria monocytogens. J Bacteriol 2010;192:3969-76.

25. Doumith M, Buchrieser C, Glaser P, et al. Differentiation of the major Listeria monocytogenes serovars by multiplex PCR. J Clin Microbiol 2004;42:3819-22.

26. Border PM, Howard JJ, Plastow GS, Siggens KW. Detection of Listeria and Listeria monocytogenes using polymerase chain reaction. Lett Appl Microbiol 1990; 1:158-62.

27. Jaradat ZW, Schutze GE, Bhunia AK. Genetic homogeneity among Listeria monocytogenes strains from infected patients and meat products from two geographic locations determined by phenotyping, ribotyping and PCR analysis of virulence genes. Int J Food Microbiol 2002;76:1-10.

28. Stepanovic S, Cirkovic I, Ranin L, SvabicVlahovic S. Biofilm formation by Salmonella spp. and Listeria monocytogenes on plastic surfaces. Lett Appl Microbiol 2004;38:42832.

29. Mead PS, Slutsker L, Dietz V, et al. Foodrelated illness and death in the United States. Emerg Infect Dis 1999;5,:607-25.

30. Hong E, Doumith M, Duperrier S, et al. Genetic diversity of Listeria monocytogenes recovered from infected persons and pork, seafood and dairy products on retail sale in France during 2000 and 2001. Int J Food Microbiol 2007;114:187-94.

31. Chen J, Luo X, Jiang L, et al. Molecular characteristics and virulence potential of Listeria monocytogenes isolates from Chinese food systems. Food Microbiol 2009;26:103-11.

32. Conter M, Vergara A, Di Ciccio P, et al. Polymorphism of actA gene is not related to in vitro virulence of Listeria monocytogenes Int J Food Microbiol 2009;137:100-5.

33. Blatter S, Giezendanner N, Stephan R, Zweifel C. Phenotypic and molecular typing of Listeria monocytogenes isolated from the processing environment and products of a sandwich-producing plant. Food Cont 2010; 21:1519-23.

34. Wiedmann M, Bruce JL, Keating C, et al. Ribotypes and virulence gene polymorphisms suggest three distinct Listeria monocytogenes lineages with differences in pathogenic potential. Infect Immun 1997;65: 2707-16.

35. Rasmussen OF, Beck T, Olsen JE, et al. Listeria monocytogenes isolates can be classified into two major types according to the sequence of the listeriolysin gene. Infect Immun 1991;59:3945-51.

36. Ericsson H, Stalhandske P, DanielssonTham ML, et al. Division of Listeria monocytogenes serovar 4b strains into two groups by PCR and restriction enzyme analysis. Appl Environ Microbiol 1995:11:3872-4.

37. Franciosa G, Maugliani A, Floridi F, Aureli P. Molecular and experimental virulence of Listeria monocytogenes strains isolated from cases with invasive listeriosis and febrile gastroenteritis. FEMS Immunol Med Microbiol 2005;43:431-9.

38. Tompkin RB. Control of Listeria monocytogenes in the food-processing environment. $\mathrm{J}$ Food Prot 2002;65:709-25.

39. Zhao T, Doyle MP, Zhao P. Control of Listeria monocytogenes in a biofilm by competitiveexclusion microorganisms. Appl Environ Microbiol 2004;70:3996-4003. 